\title{
A study to assess the knowledge regarding partograph among staff nurses
}

\begin{abstract}
Every year, out of an estimated 120 million pregnancies that occur World Wide, about half million women die because of complication of pregnancy and child birth. So there is need of skilled assistance during labour is the very important and key service to reduce the rates of maternal mortality and morbidity rates. The partograph (sometimes known as partogram) is usually a pre-printed paper form on which labour observation are recorded. The aim of partograph is to provide a pictorial overview of labour, to alert midwives and obstetricians to deviations in maternal or fetal wellbeing and labour progress. The objective of the study was to assess the knowledge regarding partograph among staff nurses.
\end{abstract}

Material \& Methods: The study was conducted in tertiary care Medical institute of Amritsar. Total 40 Staff Nurses were selected by convenience sampling technique those were working in obstetric \& gynaecological ward of SGRD hospital, vallah, Amritsar. A self structured questionnaire was used to assess the knowledge of staff nurses regarding Partograph. The data was gathered and analysed by calculating the frequency, percentage, mean, mean percentage, standard deviation and chi square.

Results: The study concluded that $57.5 \%$ of staff nurses having average knowledge, $25 \%$ staff nurses having good knowledge and remaining, $17.5 \%$ staff nurses having poor knowledge regarding partograph.

Conclusion: The partograph is considered a valuable tool in the improvement of maternity service by allowing midwives and obstetrician to display intrapartum details in a pictorial manner.

Keywords: staff nurses, knowledge, partograph
Volume 5 Issue 2 - 2019

Rajbir Kaur

Department of OBG(N), Sri Guru Ram Das College Of Nursing, India

Correspondence: Rajbir Kaur,Assist Prof, Department of OBG(N) Sri Guru Ram Das College Of Nursing, Vallah, Amritsar, India, Email getyashraj2006@gmail.com

Received: June 07, 2018| Published: April 01, 2019

\section{Introduction}

Maternal mortality remains between 500 - 1000 deaths for 100,000 live births in developing countries. India ranks very higher on the list of countries with high maternal mortality at 420 per 10,000 live births. ${ }^{1}$ In Punjab maternal mortality rate was $28 \%$ in $2012 .{ }^{2}$ Maternal morbidity and mortality rate increases because of insufficient facilities in health care settings and inadequate knowledge and attitude of plotting the partograph. During child birth, complication cannot be predicted or prevented. ${ }^{3}$ Prolonged labour and obstructed labour are major causes of maternal and newborn morbidity and mortality; they can lead to ruptured uterus, postpartum haemorrhage, infection, obstetric fistula, and foetal injury or death. Thus all women should be assessed by skilled birth attendance and timely emergency care. ${ }^{4}$ The partogram (sometimes known as partograph) is usually a preprinted paper form on which labour observation are recorded. The aim of partogram is to provide a pictorial overview of labour, to alert midwives and obstetricians to deviations in maternal or fetal wellbeing and labour progress. Partograph contain pre-printed alert and action lines. Hence skilled assistance during labour is the very important and key service to reduce the rates of maternal mortality and morbidity rates. So the aim of study is to assess the knowledge regarding partograph among staff nurses.

\section{Objective}

1. To assess the knowledge of staff nurses regarding partograph.
2. To find out the association between the knowledge score with selected demographic variables.

\section{Methodology}

Quantitative research approach with descriptive design having one point data collection was used. The study was conducted at SGRD hospital Vallah, Amritsar in May 2015. Convenience sampling were used to select 40 study subjects. Tool was consisting of two sections that is Socio-demographic profile sheet and self structured questionnaire. Socio-demographic profile sheet include age, educational status, working experience, marital status \& attended in-service education programme. Twenty one self- structured questionnaires were prepared and finalized from extensive review of literature. Questionnaire items includes components of Partograph, maternal \& fetal condition. Questionnaire was validated by experts of obstetric department. Each correct answer was given 1 mark. Questionnaire was used to assess the knowledge regarding partograph among staff nurses. After maintaining rapport and explaining the purpose of study to staff nurses, structured knowledge questionnaire was distributed.

\section{Statistical analysis}

Data was collected, organized and analyzed by SPSS version 16 . Computation of frequencies and percentage was done for the analysis of socio- demographic variables. For assessing the level of knowledge regarding partograph among staff nurses arithmetic mean and S.D 
was calculated. To find out the relationship of knowledge with socio demographic variables among staff nurses non parametric chi-square test was applied at $\mathrm{p}$ value $<0.05$.

\section{Ethical consideration}

The study had been approved by the ethical committee of Sri Guru Ram Das Institute of Medical Sciences and Research Vallah, Sri Amritsar. Written informed consent was taken from each study subject after informing them about study. The confidentiality was maintained throughout the study.

\section{Criteria for evaluation was as following}

Table 1.

Table I Maximum and Minimum obtainable score was $2 I$ and zero respectively

\begin{tabular}{ll}
\hline Partograph knowledge score & Level of knowledge \\
\hline $0-7$ & Poor \\
$8-14$ & Average \\
$15-2 \mid$ & Good \\
\hline
\end{tabular}

\section{Results}

The findings are presented in Tables 2-4.

Table 2 depicts that a majority of staff $(47.5 \%)$ are in the age group of 20-30 years and then followed by (30\%) of 30-40 years and (20\%) of $41-50$ years of age and (2.5\%) of above 50 yrs. Majority of staff $(67.5 \%)$ were of GNM Nursing, followed by $(20 \%)$ of BSC Nursing \& $(12.5 \%)$ of Post Basic Bsc. Nursing. Majority of staff $(65 \%)$ having clinical experience of more than 2 years followed by $(20 \%)$ having less than 1 year experience and (15\%) having 01-02 years of experience. Majority of staff $(55 \%)$ is unmarried and $45 \%$ of staff is married. Majority of staff $75 \%$ that never attended any in service education programme regarding partograph followed by $25 \%$ who attended in service education programme on partograph.

Table 3 \& Figure 1 reveals that $17.5 \%$ of staff nurses have poor knowledge, followed by $25 \%$ of staff nurses are having good knowledge and $57.5 \%$ of staff nurses have average knowledge. The mean of study score is 12.35 and Standard deviation is 4.023. Table 4 shows knowledge level with selected socio-demographic variables. i.e.age, qualificationclinical experience and in-service education attended are non significant at p-value 0.05 marital status found significant at p-value 0.05 .

Table 2 Socio demographic profile of staff nurses, $\mathrm{N}=40$

\begin{tabular}{|c|c|c|c|}
\hline Sr. No. & Socio-demographic variables & $\mathbf{F}$ & $\%$ \\
\hline \multirow[t]{5}{*}{ I. } & Age (In Years) & & \\
\hline & $20-30$ & 19 & 47.5 \\
\hline & $31-40$ & 12 & 30.0 \\
\hline & $4 \mid-50$ & 8 & 20.0 \\
\hline & $>50$ & I & 2.5 \\
\hline \multirow[t]{4}{*}{2.} & Qualification & & \\
\hline & GNM & 27 & 67.5 \\
\hline & B.Sc. (N.) & 8 & 20.0 \\
\hline & Post Basic B.Sc. (N.) & 5 & 12.5 \\
\hline \multirow[t]{4}{*}{3.} & Experience (In Years) & & \\
\hline & $<1$ & 8 & 20.0 \\
\hline & $\mathrm{I}-2$ & 6 & 15.0 \\
\hline & $>2$ & 26 & 65.0 \\
\hline \multirow[t]{3}{*}{4.} & Marital Status & & \\
\hline & Married & 18 & 45.0 \\
\hline & Un-married & 22 & 55.0 \\
\hline \multirow[t]{3}{*}{5.} & Attend In-Service Education Programe & & \\
\hline & Yes & 10 & 25.0 \\
\hline & No & 30 & 75.0 \\
\hline
\end{tabular}

Table 3 Level of Knowledge regarding Partograph among staff Nurses, $N=40$

\begin{tabular}{llllll}
\hline Sr. No. & Level of Knowledge & Scoring Criteria & $\mathbf{f}$ & $\%$ & Means \pm SD \\
\hline 1 & Poor Knowledge & $0-7$ & 7 & 17.5 & \\
2 & Average Knowledge & $8-14$ & 23 & 57.5 & $12.35 \pm 4.023$ \\
3 & Good Knowledge & $15-21$ & 10 & 25.0 &
\end{tabular}

Table 4 Association between knowledge level with selected Socio-demographic variables, N=40

\begin{tabular}{|c|c|c|c|c|c|c|c|}
\hline \multirow{2}{*}{ Sr. No. } & \multirow{2}{*}{ Socio-demographic Variables } & \multicolumn{3}{|c|}{ Level of Knowledge } & \multirow{2}{*}{$X^{2}$-value } & \multirow{2}{*}{ Df } & \multirow{2}{*}{ p-value } \\
\hline & & Poor & Average & Good & & & \\
\hline \multirow[t]{5}{*}{$\mathrm{I}}$. & Age (In Years) & & & & & & \\
\hline & $20-30$ & 5 & 10 & 4 & & & \\
\hline & $31-40$ & 2 & 6 & 4 & 7.648 & I & $.265^{\mathrm{NS}}$ \\
\hline & $41-50$ & 0 & 7 & 1 & & & \\
\hline & $>50$ & 0 & 0 & I & & & \\
\hline
\end{tabular}


Table Continued...

\begin{tabular}{|c|c|c|c|c|c|c|c|}
\hline \multirow{2}{*}{ Sr. No. } & \multirow{2}{*}{ Socio-demographic Variables } & \multicolumn{3}{|c|}{ Level of Knowledge } & \multirow{2}{*}{$X^{2}$-value } & \multirow{2}{*}{ Df } & \multirow{2}{*}{ p-value } \\
\hline & & Poor & Average & Good & & & \\
\hline \multirow[t]{4}{*}{2.} & Qualification & & & & & & \\
\hline & GNM & 4 & 15 & 8 & & & \\
\hline & B.Sc. (N.) & 2 & 5 & 1 & 1.226 & 4 & $.874^{\mathrm{NS}}$ \\
\hline & Post Basic B.Sc. $(\mathrm{N}>)$ & I & 3 & I & & & \\
\hline \multirow[t]{4}{*}{3} & Experience (In Years) & & & & & & \\
\hline & $<1$ & 3 & 4 & 1 & & & \\
\hline & $\mathrm{I}-2$ & 0 & 4 & 2 & 3.816 & 4 & $.43 I^{\mathrm{NS}}$ \\
\hline & $>2$ & 4 & 15 & 7 & & & \\
\hline \multirow[t]{3}{*}{4.} & Marital Status & & & & & & \\
\hline & Married & 0 & 12 & 6 & 7.115 & 2 & $.029 * *$ \\
\hline & Un-married & 7 & 11 & 4 & & & \\
\hline \multirow[t]{3}{*}{5.} & Attend In-Service Education Programme & & & & & & \\
\hline & Yes & 2 & 8 & 0 & 4.555 & 2 & $.103^{\mathrm{NS}}$ \\
\hline & No & 5 & 15 & 10 & & & \\
\hline
\end{tabular}

NB: df, Degree of freedom; NS, Non-significant(p-value $>0.05)$; ${ }^{* *}$, Significant ( $p$-value $\left.<0.05\right)$.

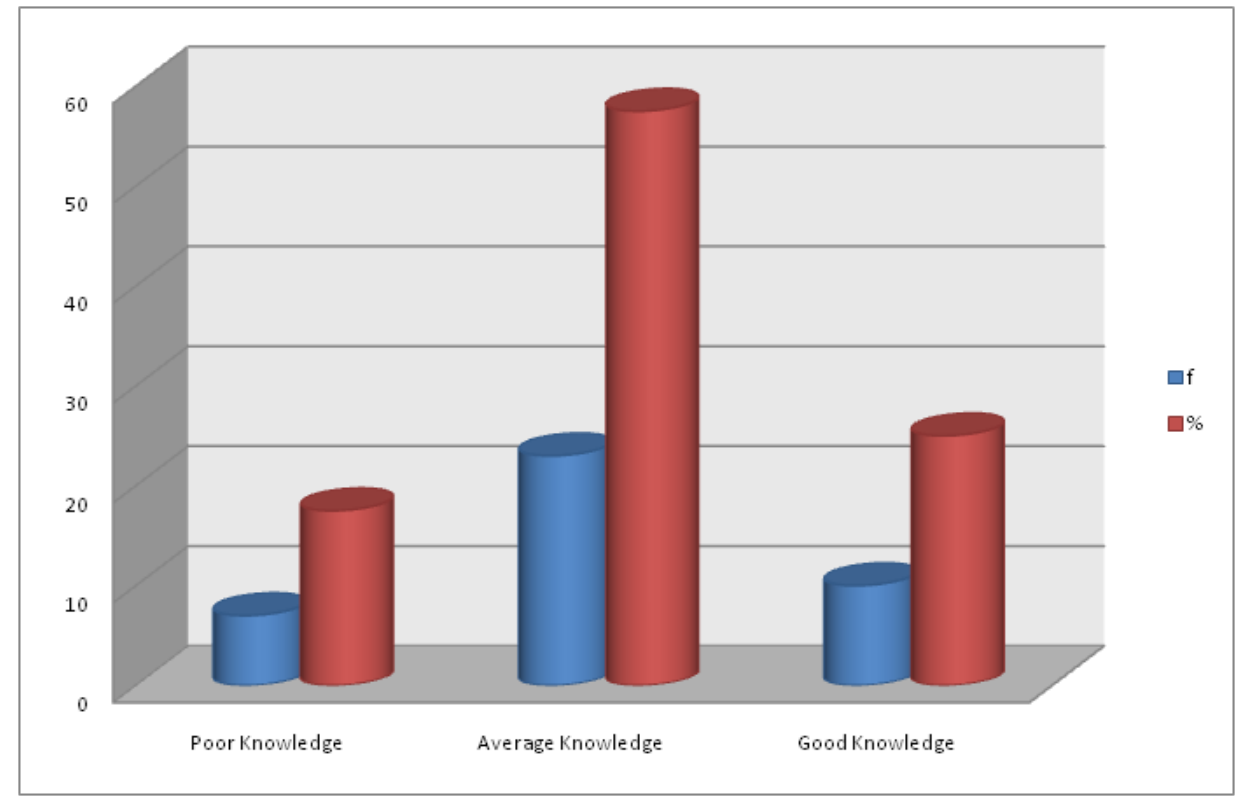

Figure I Level of Knowledge on partograph among staff nurses.

\section{Discussion}

Labour has been considered to be the most painful journey a woman ever under takes. Although it is a natural process but complications can arise at any time during its course. The partograph is considered a valuable tool in the improvement of maternity service by allowing midwives and obstetrician to display intra partum details in a pictorial manner. The result of present study revealed that $57.5 \%$ staff nurses had average knowledge, $25 \%$ staff nurses had good knowledge, $17.5 \%$ staff nurses had poor knowledge. The research study of assessment and utilization of partograph among obstetric caregivers concluded that $52.3 \%$ responded had fair knowledge $39.0 \%$ had good knowledge of utilization of partograph. ${ }^{5}$ Another Study conducted in Cameroon about knowledge and utilization of partograph in which they concluded that $33.8 \%$ respondents had average knowledge regarding partograph followed by $29.6 \%$ takes partograph as a complex tool.

\section{Conclusion}

It was concluded that Knowledge level of staff nurses regarding use of partograph is relatively less and there is no significant association of socio-demographic variables with level of knowledge of staff nurses regarding partograph except marital status. 


\section{Acknowledgments}

I appreciate and will never forget the determination and encouragement bestowed by our worthy Principal Dr. Parvesh Saini.

\section{Finances}

No separate funding was received for the study.

\section{Conflicts of interest}

The author declares there are no conflicts of interest.

\section{References}

1. Lavende T, Hart A, Smyth RMD. Effect of partograph use on outcomes for women in spontaneous labour at term. The cochrance collaboration. John Wiley and sons, Ltd. Cochrance libr. 2009;1:1-22.
2. Gupta N. Maternal mortality, Magnitude causes and consensus. Journal obstetrics and Gynecnectodat. 2004.

3. Ghirway A. Michael MD, Skilled birth attendant competence and facility readiness for managing obstetric emergencies in Eritrea. Journal of Etirea medical association. 2006;1(1).

4. Kala S, Yound Wanichsate S, Chuman S. Effect of instructional videos on the knowledge and labour practical skills of nursing students. Songkla Med J. 2008;26(2);111-121.

5. Fawole AO, Hunyimbo KI, Adekanle DA. Knowledge and utilization of the partograph among obstetric care givers in south vest Nigeria. Afr J of Reprod Health. 2008;12:22-29. 